\title{
DNA damage control then and now: a matter of life or death
}

\section{David F. Albertini ${ }^{1}$}

Published online: 15 July 2020

(C) Springer Science+Business Media, LLC, part of Springer Nature 2020

For the vast majority of oocytes in mammals in meiotic prophase from fetal through prepubertal stages of ovarian development, their fate is sealed long before hopes of being ovulated or fertilized. On the other hand, for the 100,000ish of oocytes surviving the housecleaning events of ovarian development, the chosen few getting the call to ovulate represent a make or break moment in an organisms' legacy. These survivors bypass the threats imposed by follicle selection pressures during the march to ovulation. And in the process of holding court over the steroidogenic powers of the follicle, the enclosed oocyte determines reproductive tract adaptations that will prepare for impending implantations. But their liabilities are notable over the course of this journey including both genetic and epigenetic perturbations imposed by intrinsic or extrinsic forces only slowly becoming recognized as threats to fertility. How this remarkable cell and its precious cargo are delivered to the nascent embryo intact and full of potential remains a mystery.

Long suspected based on our understanding of DNA integrity maintenance in somatic cells, the search for a DNA Damage Repair (DDR) mechanism in germ cells has yielded novel insights into how oocytes and sperm manage to oversee genetic integrity in the germline of mammals. To this audience, the matter of sperm DNA fragmentation detection and impact on IVF outcomes is well known. Much less apparent, however, is the matter of what long-lived cells like oocytes engage in to detect, protect, and enable the viability of oocytes packaged away in their follicle niches for so many years waiting for the prospect of their selection being realized.

DNA damage, and the mechanisms deployed to both recognize and repair lesions in our genomes, has been the stuff of contemporary cancer cell biology for decades now. And rightly so. Many new drugs capable of targeting, disarming, and bringing about the demise of cancerous tumors and their metastatic counterparts now exists in the oncology field based on

David F. Albertini

eicjarg@gmail.com

1 Bedford Research Foundation, Bedford, MA, USA insights gained from many years of research into the nuances of cell cycle control. But these therapeutics are not without side effects with respect to the reproductive system, with consequences such as germ cell loss being the focus of efforts in the oncofertility and fertility preservation campaigns. To be clear, the DNA damage incurred by patients undergoing chemotherapy or radiation therapy poses clear and present threats to future reproductive health. What safeguards may be in place to correct and repair the damage incurred by these or other exposures over a females lifetime has not been clear.

Last month, McGinnis and colleagues reported in a mouse study the negative impact of treatments on the follicle reserve and even on embryo quality following chemo treatments (Long-term imatinib diminishes ovarian reserve and impacts embryo quality https://doi.org/10.1007/s10815-020-0177). And this month, Subira and colleagues add to the matter of side effects in humans (Impact of ABVD chemotherapy on ovarian reserve after fertility preservation in reproductiveaged women with Hodgkin lymphoma, https://doi.org/10. 1007/s10815-020-01844).

Finally, the science underlying loss of fertility in cancer patients is one thing, as discussed below. The matter of access to care is quite another. Contextualizing this imperative from a global perspective and with the COVID-19 pandemic front and center, Salama and colleagues bring this important topic down to its most fundamental of principles, practically speaking (Installing oncofertility programs for common cancers in limited resource settings (Repro-Can-OPEN Study): An extrapolation during the global crisis of Coronavirus (COVID-19) pandemic, https://doi.org/10.1007/s10815-02001821).

For an insightful look into the basic biology of the ovarian DDR, we urge our readership to examine the paper coming from the laboratory of Karla Hutt at Monash University in Melbourne. Although using a mouse model, this tour de force draws upon the tools of contemporary molecular and cellular biology to tease apart not only how th oocyte manages genome integrity after an external insult but tracks the outcome of this intraovarian system on the fate of embryos temporally removed from the original insult, in this case gamma irradiation [1]. 
Many mouse studies appeared prior to this work [2] with studies linking mouse to human biology [3] and evidence of a repair capacity in human oocytes previously noted [4]. Among the significant contributions, especially with respect to the role of the DDR in breast cancer patients carrying mutations in the BRCA genes, are those from the group of Oktay [5], with prospects for limiting DNA damage in males on the horizon [6]. Whether crossing over of this field will further bridge the gap between reproductive medicine and cancer biology remains to be shown. Bear in mind, however, that provocative signs of such interdisciplinary fertilization are emerging to suggest so [7].

This month, we deliver an array of basic science and clinical medicine reports but add to our lineup papers expressing opinions and viewpoints we hope our readership will take to heart, given the circumstances we all find ourselves in. We also recognize and thank several board members who will be leaving the JARG family after many years of service. To Jemma Evans, Elpida Fragouli, and Nathan Treff, thanks for your selfless efforts over these years. And, to Teresa Woodruff, a founding member of the editorial board back in 2009 and founder par excellence of the Oncofertility Consortium, we extend our gratitude and best wishes as you take your career to the next well-deserved level.

\section{References}

1. Stringer JM, Winship A, Zerafa N, Wakefield M, Hutt K. Oocytes can efficiently repair DNA double-strand breaks to restore genetic integrity and protect offspring health. Proc Natl Acad Sci U S A. 2020;117(21):11513-22.

2. Carroll J, Marangos P. The DNA damage response in mammalian oocytes. Front Genet. 2013;4:117.

3. Titus S, Li F, Stobezki R, Akula K, Unsal E, Jeong K, et al. Impairment of BRCA1-related DNA double-strand break repair leads to ovarian aging in mice and humans. Sci Transl Med. 2013;5(172):172ra21.

4. Coticchio G, Dal Canto M, Guglielmo MC, Albertini DF, Mignini Renzini M, Merola M, et al. Double-strand DNA breaks and repair response in human immature oocytes and their relevance to meiotic resumption. J Assist Reprod Genet. 2015;32(10):1509-16.

5. Oktay KH, Bedoschi G, Goldfarb SB, Taylan E, Titus S, Palomaki $\mathrm{GE}$, et al. Increased chemotherapy-induced ovarian reserve loss in women with germline BRCA mutations due to oocyte deoxyribonucleic acid double strand break repair deficiency. Fertil Steril. 2020;113(6):1251-60 e1.

6. Stobezki R, Titus S, Halicka D, Darzynkiewicz Z, Oktay K. Declining BRCA-mediated DNA repair in sperm aging and its prevention by Sphingosine-1-phosphate. Reprod Sci. 2020;27(3):940-53.

7. Thomas F, Giraudeau M, Renaud F, Ujvari B, Roche B, Pujol P, et al. Can postfertile life stages evolve as an anticancer mechanism? PLoS Biol. 2019;17(12):e3000565.

Publisher's note Springer Nature remains neutral with regard to jurisdictional claims in published maps and institutional affiliations. 